\title{
Factors Affecting Exercise Adherence Behavior of University Students in Upper Northeastern, Thailand
}

\author{
Poosanapas Somnil ${ }^{1} \&$ Thawichai Khaothin ${ }^{2}$ \\ ${ }^{1}$ Faculty of Science, Udon Thani Rajabhat University, Udon Thani, Thailand \\ ${ }^{2}$ Institute of Science, Suranaree University of Technology, Nakhon Ratchsima, Thailand \\ Correspondence: Poosanapas Somnil, Sports Science Program, Faculty of Science, Udon Thani Rajabhat \\ University, 64 Tahan Rd., Udon Thani, 41000, Thailand. Tel: 66-89-665-5248. E-mail: poo.somnil@gmail.com
}

Received: August 8, 2015

doi:10.5539/ass.v12n12p205
Accepted: October 24, 2016 Online Published: November 16, 2016

URL: http://dx.doi.org/10.5539/ass.v12n12p205

\begin{abstract}
This research was aimed to study the meaning of adhere to exercise by the experience of university students who adhere to exercise. The experience and model of a lifestyle that has adhered to an exercise of those adhere to exercise. The phenomenological study, data was collected through in-depth interviews individually. The groups of main contributors were 12 university students who adhere to exercise by checking the reliability of the data and conclusions by the contributor. Data was analyzed by the researcher used the phenomenological analysis of data. The results showed students who adhere to exercise definite exercise adherence that is to exercise regularly and exercise it for a long time with feeling like exercise which is thought of exercise is a part of life. It makes the body healthy and to have fun and develop them. The experience and model of lifestyle adhere to exercise that can be divided into three phases: 1) before performing exercise 2) began performing an exercise, and 3) when it adheres to exercise. It was found that in all phases of the study can be divided into two factors related to the second side is the side of the personal and the environmental factors.
\end{abstract}

Keywords: exercise adherence, phenomenological study, in-depth interview

\section{Introduction}

\subsection{Introduce the Problem}

The lifestyle of people in society today, rather it is a physical activity that is less than the past which is why it's important to the quality of life. Resulting in worse health compared to the past, the rate of deterioration of conditions can cause death and more. The study found that lack of exercise can cause risk factors for chronic disease (Hagger \& Chatzisarantis, 2008) such as cancer (Byers et al., 2002), diseases related to the cardiovascular system and blood circulation (Hooper et al., 2001), obesity (Ross et al., 2000), diabetes (Fritz et al., 2006) with many studies that point out the importance of the changes of the body and mind from exercise training programs. For example, benefits of exercise such as reducing the risk of heart disease, high blood pressure, diabetes and colon cancer, a healthy and strongly bones, weight change for the better sleep, reduce anxiety and depression, enhancing self-esteem (Marcus \& Forsyth, 2003) by the body and mind will benefit from an exercise program that is sufficient. It must have designed the program based on the principles of FITT, the type, frequency, intensity and duration (time) of (Martin et al., 2000), as appropriate jogging 3-5 times a week in the 60-90 percent of the maximum pulse rate and exercise 20-60 minutes per session which is a form of exercise that affect health such as cycling, walking quickly (15-20 minutes per mile), dance, walking, playing golf, playing volleyball, etc (Marcus \& Forsyth, 2003). For the United Kingdom authorities relating to the promotion of health has been promoted through various media to encourage people to focus on healthcare with exercise which aims of the public in good health free from preventable illness in addition to the benefits of enhancing health. Medical exercise has been used as a remedy for many diseases such as cardiovascular disease, diabetes, colon cancer, arthritis, bone degeneration, obesity (Brunet, Plotnikoff, Raine, \& Courneya, 2005; Sallis \& Owen, 1999 cited in Wolfe, 2008), stress disorder (Buckworth \& Dishman, 2002), anxiety disorder (Petruzzello et al., 1991), which was found to have therapeutic benefits as well.

\subsection{Explore Importance of the Problem}

Buckworth \& Dishman (2007) mention that the adherence must be reframed to consider patterns of physical 
activity over the lifespan by efforts must be made to study the patterns of physical activity over time and in a different population, considering unique cultural and economic-political differences within and among countries. So, it should encourage people to exercise and when people choose to exercise, they should be encouraged to exercise regularly and consistently. Promote adherence to exercise, it should be done since their youth (15-24 years), during which the young are as important to the nation's future. The research to support that exercise behavior during childhood can be used as predictors of exercise or physical activity behavior in young adults (Coakley \& White, 1992; Risto, Xiaolin, Lauri, \& Jorma, 2000, cited in Jermsuravong, 2006).

Support and encourage individuals exercise at an early age is the best age. Since age is the age of knowledge and development of body and mind. When the bodies healthy, it will make learning more efficient as well as students who will be an asset to the nation are crucial to the development in the future should turn to exercise and healthy eaters and more. When entering the age of 30 years or more, it will have the opportunity to diseases such as heart disease, hypertension, diabetes, etc. Therefore, the best approach is prevention. Exercise regularly and continuously can cultivate since childhood. What is important for promoting exercise behavior in childhood, it should be to maintain health and prevent disease in the long term from moving into adulthood and old age to healthy and strong.

Therefore, it should encourage students to exercise. When students chose to exercise it should be encouraged to exercise constantly and consistently by promoting adherence to exercise should start from a young age is the age range of 15-24 years which research at last found exercise behavior was younger could predict the behavior of exercise or physical activity in older adults. A study by Dishman $(1988,1994)$ found that 50 percent of those who attend fitness programs to quit or stop exercising for a period of 3-6 months. McAuley (1992) found that the basis for success to encourage individuals born adhering to an exercise program, it is also understood that the little which Yoo (1991) says that the behavior of adhering to exercise a relevant factor which cannot be separated from each other, individual factors, social factors and cognitive factors.

\subsection{State Hypotheses and Their Correspondence to Research Design}

Exercise adherence is a concept about the adhesion (sticking to) an exercise program. The description on its adherence to exercise is directly related to the concept of motivation (Brehm, 2004) by creating incentives to help individuals adhere to exercise and makes an objective (goal) in mind, the impulses is a driving force within the inner drive or the intention to cause a person's ideas and actions consistent with Anshel (2007) said the motive was a trend. Human behaviors have a direction and choose to commit to anything. The tendency of such behavior will remain will be the goal for achievement. The decision of the parties to exercise to reflect its focus on the needs and achievement expression, Weinberg \& Gould (2007) said that motivation is what determines the direction and the willingness to act. Human behavior is directed to retreat or face the situation and a willingness to conduct or attempt to achieve that goal. So, the incentive is relevant and important to the promotion of adhering to exercise behavior.

The recent study found that studies on exercise behavior are theories or models such as the social cognitive theory, the theory of planned behavior, the transtheoretical model, self-determination theory, etc. Various theories, these are accepted and widely used in psychological research, exercise and health (Biddle \& Fuchs, 2009), which are useful to explain the reason and the motive to affect the conduct of the exercise or the lack of exercise as well. The social cognitive theory describes learning and behavior modification by learning from the interaction between individuals influences the individual (personal) behavior (behavioral) and the environment (environmental). It is believed that the efficacy of their own abilities (Self-efficacy) can affect the action. Each person may be different, but cannot be expressed in the quality of work vary. The efficacy of the self is the subject of judgment ability (Bandura, 1986, 1997, 2001). For the theory of planned behavior, a theory that developed the theory of reasoned action (Ajzen \& Fishbein, 1980, cited in Weinberg \& Gould, 2003) a theory that describes the reason for the expression of individual behavior, the intention in relation to the change in behavior. The intention for this to happen when it is the result of three factors, the psychological factors is the attitude, norms and perceived behavioral control (Ajzen \& Madden, 1986 cited in Weinberg \& Gould, 2003). Model, the theory of change was developed to explain the motivations of individuals for behavior change by focusing on the individual decision of the intended change. This model also explains the behavior change process and the development process in order to adhere to the concept of when and how which is a medium that is affecting behavior change. Equilibrium in the decision (decisional balance) related to the concept of benefits (pros) to waste (cons) in order to change behavior and another thing is the belief in their own abilities (Self-efficacy) (Prochaska et al., 1992 cited in Biddle \& Mutrie, 2008). And the last is the theory of self-determination, which is a theory of motivation and personality of the person associated with a person can choose activities any freely without outside influences. Choosing to self-determination is an independent not 
associated with reward or encouragement from the environment. Self-determination theory, it is geared to the level of self-determination of the behavior. The knowledge gained from this theory can help understand people who participated in the exercise to be able to know what kind of motivated individual to influence the activity of selected actions (Deci \& Ryan, 2002).

Various theories, the above resulted in a better understanding of the psychosocial factors that affect performance behavioral changes in fitness. The party has no ideas to change behavior to the behavior of the action. However, psychosocial factors did not influence such behavior only change but there is an important role and can be used to explain the party decided to adhere to exercise regularly as well (Brehm, 2004; Chogahara et al., 1998; McAuley, 1992; McAuley \& Jacobson, 1991; Dzewaltowski et al., 1990). However, there is no such clarity since the academic papers adhere to exercise a little and still lacks measuring a specific (Nigg et al., 2008). Therefore, the idea for the study of psychosocial factors have according to various studies as mentioned above in order to be able to predict the behavior of adhere to the exercise of the party clearly and specifically involve the researcher how to present the data in the study used the qualitative research by means of studying the phenomenon of the experience meets the reality of those who are committed to fitness to be clear, accurate, complete, apart from the experience of a life committed to the exercise by focusing on retention deeply natural. This will allow them to find and access the information in its entirety. So, education this will reflect and understand the factors that affect the behavior of adhering to the exercise of a clear and specific. The results of this study will be a model or prototype model of a life adhere to an exercise of those who adhere to exercise. This is a pattern that is specific to be applied in determining the strategic tactics to encourage individuals are university students who will have to grow to maturity and strength of the back their lifestyle, adhere to exercise and how to spot reduce, stop or quit exercise.

\section{Method}

\subsection{Research Design}

This research is a qualitative research, a phenomenological research methodology, using the method of data collection by in-depth interviews and the observation. The objective is to describe and explain the experience of a lifestyle that is adhered in the exercise of those who adhere to the exercise by studying the phenomenology as a way to understand the direct experience of those who adhere to exercise fully profound and can make a model of a lifestyle that is adhered in the exercise of those who adhere to the exercise.

Factors that influence adheres to exercise, knowledge, theory and study form basis of social cognitive theories (model of exercise behavior) including the social cognitive theory, the theory of planned behavior, the transtheoretical model, the self-determination theory and from the document, research related to the behavior of adhering to exercise.

\subsection{Sampling Procedures}

Population and samples used in this study were male students - undergraduate women aged 18-22 years who are adhere to exercise who practice physical activities on a regular basis for at least three days a week and exercise for at least six months samples used in this study of 12 people ( 7 male, 5 female) who were in direct contact with the primary everyone and contributors to anyone willing to interviews.

\subsection{To Assess the Reliability of the Information}

The evaluation of the data collected from the questions of the interview and researcher who collected the data. The researchers conclude taken a major step three phases, 1) Reliability (Credibility), reliability of the data, the researchers used the method to verify the information from monitoring centers, information (data triangulation) by examining data obtained from sources such as the mean time, if different times are the same whether or not the source location means it. Information different locations are the same or not and if the person means a person who provides information to the data is the same or not by using different periods in the morning and also store information such as the need for a long period was abandoned for the time being, they returned to collect the same information over again in the place and the people. In examining this research can be done by talk. The different parties and different locations, where to find the answer in each subject each issue of the researcher to chat inquiries from several groups are gathered in various locations, fitness activities differ in conversation. Sometimes, though a different group activity, it may be the same person who provides information may also be checked by the data (member checking), If all the data that has found the same, research has shown that the information is accurate. 2) The constant research (Consistency) in this study, the researchers interviewed the controls are stable for an interview every time. The researcher will interview only. And 3) to confirm the findings (Confirm ability) to collect and analyze data, the researchers will collect evidence and information in the 
research. So, you can check back at any time. In presenting the findings, the researchers will present data from the idea of providing information not directly from the ideas of researchers to eliminate bias. From that process, the researchers are confident that the information was credible and can be analyzed for the research.

A qualitative design was used to explore participants' views on people who have regularly exercise behavior. A phenomenological study was used. The aim is to capture participants experiences of life by letting them talk. The researcher carefully examines these reported experiences, reflects on the perceptions and assumptions that underpin these experiences and finally interprets the experiences. It is this process of participants interpreting their experiences to report them and then the researcher interpreting the participants' interpretations by a Phenomenological study. So, this research is qualitative research methodology, phenomenological study means of data collection, in-depth interview with observation. The qualitative research will focus on the study of information from people who are qualified. Experience in the scrap and can provide information not fully meet them phenomenon of interest. The data collection is required to select the specific data. Meet the criteria set by the researchers. The researchers used semi-structured interview individualized guidance. Interview by problems and research objectives the framework for research to determine the issues.

\section{Results}
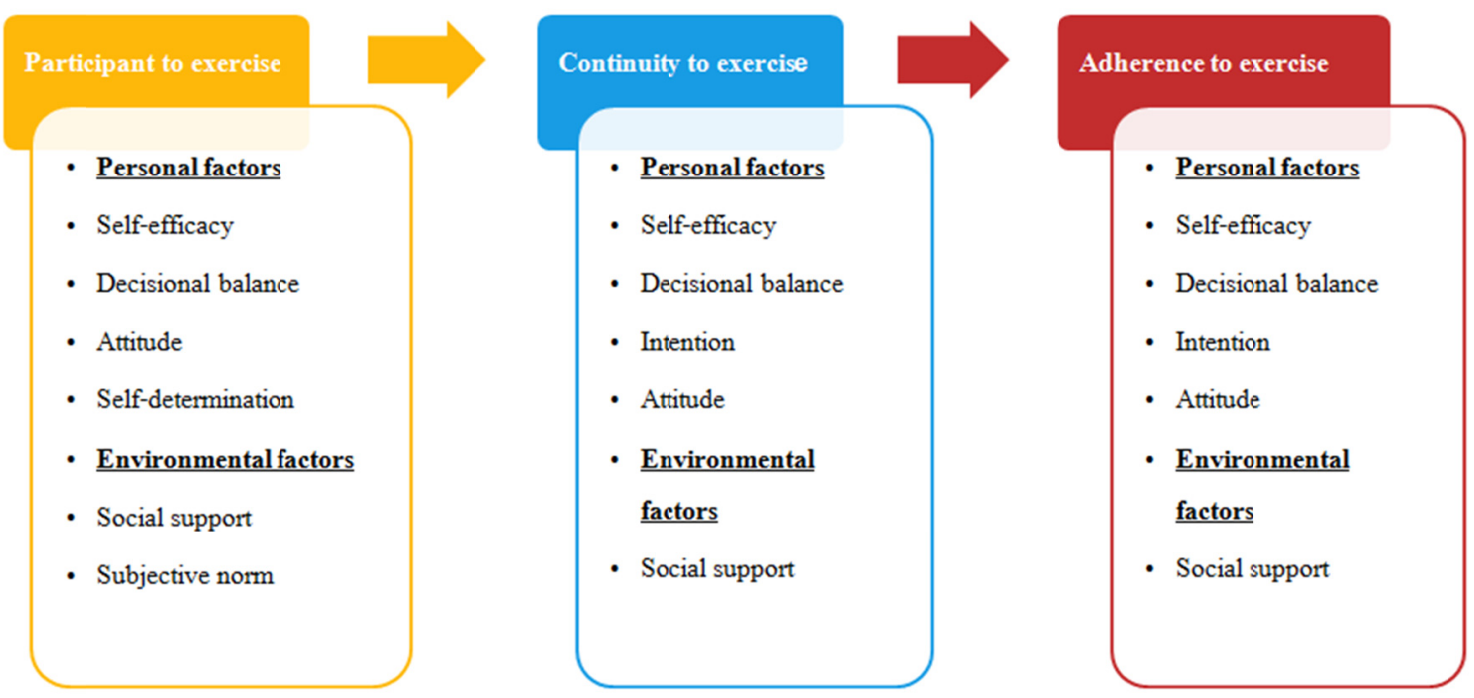

Figure 1. Factors affecting exercise adherence behavior of university students in Upper Northeastern, Thailand

The study of factors affecting adhere to exercise behavior of university students, the research results were as follows;

The definition of adhering to exercise by the experience of university students who adhere to exercise is to exercise regularly and exercise have been established for a long time with feel like exercise, the idea that exercise is a part of life, then make the body strong and healthy, have fun and want to develop themselves.

Experience of lifestyle adherence to exercise of university students who adhere to exercise can be divided into three phases;

During the first stage, before performing physical activities that admission to the practice of physical activity at the start of each person experienced the factors involved is believed to be one of their own by imitation from a template. In addition, social support, family, friends, teachers parity in decision-making for the benefit of the exercise, a positive attitude toward exercise the Norm and to decide for themselves influence the exercise as well.

During the second stage, to perform physical activities that once a person enters into a period of physical activity and those who practice it. From the experience of the individual factors involved that affecting the exercise still further continue to have faith in their own abilities, specifically, that they continue to follow the situation and practice it with their own experience of successful past. In addition, social support, family, friends, teachers parity in decision-making for the benefit of the exercise, a positive attitude and willingness to exercise influence still continues to exercise as well. 
During the third stage, when adherence to exercise found that when people go through a phase of continued fitness to practice it. From the experience of the individual factors involved that can affect adherence to exercise further continue to have faith in their own abilities, specifically, that they continue to follow the situation and practice well from their own experience of successful past. There is an imitation from a template. In addition, social support, including family, friends, co-exercise, equilibrium in the decision on the benefits of exercise, intention to adhere to the next exercise and have a positive attitude to change exercise also influence adherence to exercise as well.

\section{Discussion and Conclusion}

By outlining the implications of adhere to the exercise by the experience of university students who are adhere to exercise that is to exercise regularly and exercise has been established for a long time with feel like exercise, the idea that exercise is a part of life, then make the body strong and healthy have fun and want to develop themselves. The meaning of this is consistent with Anshel (2007) said the most important aspect of the exercise is that the person must have the desire and motivation to act by a study of motivation is an important exercise. Then make the body strong and healthy have fun and want to develop them. This person is motivated to exercise make no goals and no momentum. Finally, do not choose to exercise. A study by Anshel (2007) also found that people who exercise it, the lack of motivation to exercise, it may result in the termination of activities in the future. The motivation is the tendency of human behavior with the direction and is selected identify themselves in order to do something. The tendency of such behavior will remain will be a target for achievement. Therefore, the decision of individuals to exercise to reflect a focus on the needs and achievement expressed.

The study experience lifestyle of adherence to an exercise of university students who are adhered to exercise that can be divided into three phases: 1) before performing physical activities phase, 2) to perform physical activities phase and 3) when adherence to exercise phase. It was found that in all phases of the study can be divided into two factors related to the second side is the side of the personal and the environmental factors namely the stage before performing physical activities were factors in a person's personal beliefs their own ability to change behavior by having a positive attitude toward exercise. The parties recognize the benefits that will change behavior and motivation from within their own fitness. The environmental factors are personally supported by individuals who have made a significant impact on the changing behavior. Later I began my practice of physical activity and a commitment to exercise common factors involved as well, namely factors of individuals, where people still have faith in their own ability to change behavior, next with the intention and has a positive attitude toward exercise. The parties continue to recognize the benefits that will follow it any further activity on the part of the environmental factors. People continue to be supported by individuals with significant impact on these ideas make him practice the following exercises.

The main thing that the study found in the first practice of physical activity and a commitment to exercise found people have faith in their own ability to change individual behavior which is a factor as a result of the imitation of that template can be explained by the concept of learning by observation. (Observational learning) of Biddle \& Fuchs (2009) and Bandura (2001) said most of the human learning occurs through observation by observing the behavior of the model. The learning model is the only model to convey the idea and expression simultaneously observing a good fit will result in the ability to express them as satisfied and individuals can successfully change behavior. The model shows the observed behavior is complex and you can do it there is a sense of personal satisfaction. So, it makes sense that he observed practice can be achieved if a real effort and indomitable. The term began to practice physical activities and when adherence to exercise found people have faith in their own ability to change their behavior as a result of the experience of the successful, Bandura. (2001) noted that the success will increase the capacity of their own ability. People believed that he could and would be necessary to increase the skills to be successful again, Bandura believed to be the most effective way to improve the efficacy of their own since it is a direct experience success thus enhance their own capabilities who to believe he can do it. Therefore, in order to improve the efficacy of their need to train skilled enough to succeed together to give the perception that they have the ability to do so. He will use the skills training most effectively individuals who perceived that they were able to not give up anything easy. I will try to work to achieve the desired goal. The important thing from another study found. The major, a person is amenable to environmental factors influential persons from the exercise can explain the principles of Ajzen \& Madden (1986 cited in Weinberg \& Gould, 2003) said that the norms (subjective norm) are believed to be influenced by someone else, as if we are never exercise I have faith in people is vital to their own. The person could be a family friend, a confidence, if these people tell you to do exercise you are more likely to exercise, according to the norms and principles of recognition of individuals on the expectations or needs of the society towards them to act or not to act in any behavior. This stems from the belief of the individual to the needs of society (normative beliefs), 
especially close ones, such as the family, so they want to make sure that they show that one out, which in this behavior exercise. So, if others encourage behaviors that we do have a good attitude with it. It is highly possible that we will do that behavior.

If focusing on cultural differences between Asian and Western participants, the present study resulted seem that have a difference in terms of the relationships among reasons for exercise and exercise participation. The results that American students exercised for body-related reasons is consistent with previous studies that have shown the primary motivations for exercise participants were body-related or extrinsic motivations (Frederick \& Ryan, 1993; Ryan \& Frederick, 1997, cited in Yan, 2008). Although American women exercised more for body-related reasons than did Thai women, Thai women may also want to lose weight or to be physically attractive. Research has shown that Thai women are slimmer than American women, and there are more Thai women who try to lose weight than American women. It seems related Yan (2008) that said the fact that Chinese women want to lose weight more but are less physically active than American women may be because Chinese women tend to use diet and other ways to control weight and enhance their Physical Attractiveness. Among the different ways to lose weight, $57.5 \%$ of Chinese women were using or had used diet as a way to lose weight (Yan et al., 2006), whereas among American women, $47 \%$ used diet to lose weight, and $41 \%$ used exercise plus diet to lose weight. Chinese college women seem to be more likely to use diet as a way to lose weight than American college women.

Important conclusions from this study to understand what to do, people to start the habit of exercise which is a great challenge but understanding to preserve the character of a person in the exercise to ensure that the following behavior is more difficult. This is what the research is to study how to make a personal commitment to exercise. The discovery is to promote factors and environmental factors to simultaneously comply with Yoo (1991) stated that the behavior of adherence to exercise a combination indistinguishable (complex) of interaction between the factors of individual factors, social factors, and cognitive factors and are consistent with Irwin et al. (2004) who said that would encourage individual adherence behavior to join an exercise program for a period of time, it must be understood that as a result of the influence of variables on the basis of population (Demographic) Physiology (Physiologic) and psychosocial variables (Psychosocial). The feedback from this research, according to studies, experiences and lifestyle factors that influence adherence to exercise behavior of university students who are adhered to exercise each time a relationship since the first practical exercise activity during the practice of physical activity and a range of exercise adherence. So, who is responsible for encouraging people to exercise to make people adhere to exercise, it should promote continued support. The style of living to adhere to the exercise of university students who are adhered to exercise of this research will form a better understanding of the various factors, psychosocial, which used to be there should be a strategic advantage, create a program to promote physical activity in accordance with hence the need to develop programs to promote adherence to physical activity for students in the future which is a long-term program. The program was created to promote exercise it must cause the development of a person's thoughts and must conform to the psychosocial factors that would affect the exercise period of such the findings from this research. Moreover, should be studied by other methods. In addition, qualitative research phenomenological study in university students who adhere to exercise to get to know the research that is consistent or different and the final results of this research should lead to a framework for the introduction of quantitative research to expand the findings to the population or other target groups.

\section{Acknowledgments}

The author would like to express sincere gratitude for Udon Thani Rajabhat University, Udon Thani, Thailand.

\section{References}

Anshel, M. (2007). Conceptualizing applied exercise psychology. The Journal of the American Board of Sport Psychology, 1.

Bandura, A. (1986). Social Foundations of Thought and Action: A Social Cognitive Theory. Englewood Cliffs, Prentice-Hall, New Jersey.

Bandura, A. (1997). Self-efficacy: The exercise of control. New York: W.H. Freeman.

Bandura, A. (2001). Social cognitive theory: An agentive perspective. Annual Review of Psychology, 52, 1-26. http://dx.doi.org/10.1146/annurev.psych.52.1.1

Biddle, S. J. H., \& Fuchs, R. (2009). Exercise psychology: A view from Europe. Psychology of Sport and Exercise, 30, 1-10. http://dx.doi.org/10.1016/j.psychsport.2009.02.011

Biddle, S. J. H., \& Mutrie, N. (2008). Psychology of physical activity: Determinants, well-being, and 
interventions (2nd ed.). New York: Routledge.

Brehm, B. A. (2004). Successful Fitness Motivation Strategies. United States: Human Kinetics.

Buckworth, J., \& Dishman, R. K. (2002). Exercise psychology. United States: Human Kinetics.

Buckworth, J., \& Dishman, R. K. (2007). Exercise adherence. In G. Tenenbaum, \& R. C. Ecklund (Eds.), Handbook of sports psychology (3rd ed.). Hoboken, NJ: John C. Wiley \& Sons, Inc. http://dx.doi.org/10.1002/9781118270011.ch23

Byers, T., Nestle, M., McTiernan, A., Doyle, C., Currie-William, A., \& Gansler, T. (2002). American Cancer Society Guidelines on Nutrition and Physical Activity for Cancer Prevention: reducing the risk of cancer with healthy food choices and physical activity. CA-Cancer Journal of Clinicians, 52, 92-119. http://dx.doi.org/10.3322/canjclin.52.2.92

Chogahara, M., O’Brien Cousins, S., \& Wankel, L. M. (1998). Social influences on physical activity in older adults: A review. Journal of Aging and Physical Activity, 6(1), 1-17. http://dx.doi.org/10.1123/japa.6.1.1

Deci, E., \& Ryan, R. (2002). Handbook of self-determination research. Rochester, New York: University of Rochester Press.

Dishman, R. K. (1988). Exercise adherence: Its impact on public health. United States: Human Kinetics.

Dishman, R. K. (1994). Advances in exercise adherence. Human Kinetics, United States.

Dzewaltowski, D. A., Noble, J. M., \& Shaw, J. M. (1990). Physical activity participation: Social cognitive theory versus theory of reasoned action and planned behavior. Journal of Sport and Exercise Psychology, 12, 388-405. http://dx.doi.org/10.1123/jsep.12.4.388

Fritz, T., Wandell, P., Aberg, H., \& Engfeldt, P. (2006). Walking for exercise - does three times per week influence risk factors in type 2 diabetes? Diabetes Research and Clinical Practice, 71, 21-27. http://dx.doi.org/10.1016/j.diabres.2005.06.002

Hagger, M., \& Chatzisarantis, N. (2008). Self-determination theory and the psychology of exercise. International Review of Sport and Exercise Psychology, 1(1), 79-103. http://dx.doi.org/10.1080/17509840701827437

Hooper, L., Summerbell, C. D., Higgins, J. P. T., Thompson, R. L., \& Capps, N. E. (2001). Dietary fat intake and prevention of cardiovascular disease: Systematic review. British Medical Journal, 322, 757-763. http://dx.doi.org/10.1136/bmj.322.7289.757

Irwin, M. L., Tworoger, S. S., Yasui, Y., Rajan, B., \& McVarish, L. (2004). Influence of demographic, physiologic, and psychosocial variables on adherence to a yearlong moderate-intensity exercise trial in postmenopausal women. Preventive Medicine, 39, 1080-1086. http://dx.doi.org/10.1016/j.ypmed.2004.04. 017

Jermsuravong, W. (2006). The Influence of Exercise Motivation on Exercise Behavior in Thai Youth (PhD thesis). Burapha University, Thailand.

Marcus, B. H., \& Forsyth, L. H. (2003). Motivating people to be physically active. Human Kinetics, United States.

Martin, S. B., Morrow, J. R., Jackson, A. W., \& Dunn, A. L. (2000). Variables related to meeting the CDC/ACSM physical activity guidelines. Medicine and Science in Sports and Exercise, 32, 2087-2092. http://dx.doi.org/10.1097/00005768-200012000-00019

McAuley, E. (1992). Understanding exercise behavior: A self-efficacy perspective. In G. C. Roberts (Ed.), Motivation in Sport and Exercise (pp. 107-127). Human Kinetics, United States.

McAuley, E., \& Jacobson, L. (1991). Self-efficacy and exercise participation in sedentary adult females. American Journal of Health Promotions, 5(3), 185-207. http://dx.doi.org/10.4278/0890-1171-5.3.185

Nigg, C. R., Borrelli, B., Maddock, J., \& Dishman, R. K. (2008). A theory of physical activity maintenance. Applied Psychology: An International Review, 57(4), 544-560. http://dx.doi.org/10.1111/j.1464-0597.2008. 00343.x

Petruzzello, S. J., Landers, D. M., Hatfield, B. O., Kubitz, K. A., \& Salazar, W. (1991). A meta-analysis on the anxiety-reducing effects of acute and chronic exercise. Sports Medicine, 11, 143-182. http://dx.doi.org/10.2165/00007256-199111030-00002

Ross, R., Freeman, J. A., \& Janssen, I. (2000). Exercise alone is an effective strategy for reducing obesity and 
related comorbidities. Exercise and Sport Science Review, 28, 165-170.

Weinberg, R. S., \& Gould, D. (2003). Foundations of Sport \& Exercise Psychology (3rd ed.). Human Kinetics, United States.

Weinberg, R. S., \& Gould, D. (2007). Foundations of Sport \& Exercise Psychology (4th ed.). Human Kinetics, United States.

Wolfe, M. E. (2008). An Evaluation of an Exercise Adherence Intervention Using the Social Cognitive Theory. (Ph.D. Thesis). The Ohio State University.

Yan, Z. (2008). Psychological Factors Related to Reasons for Exercise: A Comparative Study Between Chinese and American College Students (M.S. Thesis). Bowling Green State University.

Yan, Z., Sun, P., Wang, W., Ma, W., Liu, H., \& Chu, X. (2006). The weight reducing behavior and influencing factors in female undergraduates in Beijing. Journal of Beijing University of Physical Education, 29, 127.

Yoo, J. (1991). Analyses of multidimentional factors influencing adherence to exercise. Korean Journal of Sport Science, 3, 84-93.

\section{Copyrights}

Copyright for this article is retained by the author(s), with first publication rights granted to the journal.

This is an open-access article distributed under the terms and conditions of the Creative Commons Attribution license (http://creativecommons.org/licenses/by/4.0/). 